\title{
PENGARUH MEDIA PEMBELAJARAN AUDIO VISUAL DAN ALAT PERAGA EDUKATIF TERHADAP HASIL PERKEMBANGAN ANAK DI RA AL KHODIJAH PURWOREJO KECAMATAN NGUNUT KABUPATEN TULUNGAGUNG
}

\author{
${ }^{1}$ Murtiyah \\ ${ }^{2}$ Adi Wijayanto \\ ${ }^{3}$ Andi Asrifan \\ ${ }^{1,2}$ Institut Agama Islam Negeri Tulungagung \\ ${ }^{3}$ Universitas Muhammadiyah Sidenreng Rappang
}

\begin{abstract}
ABSTRAK
Penelitian dalam skripsi ini dilatar belakangi bahwa penggunaan media pembelajaran yang tepat dapat memberikan stimulasi perkembangan anak usia dini. Pemilihan dan penggunaan media pembelajaran yang tepat dapat menstimulasi perkembangan anak usia dini di RA Al Khodijah Purworejo Ngunut Tulungagung. Media audio visual memberikan suara dan gambar yang bergerak sehingga dapat menarik minat anak dalam pembelajaran dan mempengaruhi kecerdasan bahasa anak. Sedangkan pembelajaran dengan menggunakan APE akan mempermudah dan memberikan kesempatan pada anak untuk berimajinasi, berfikir kreatif, menciptakan sesuatu yang baru dan menemukan berbagai alternatif dalam pemecahan masalah.

Peneliti menggunakan pendekatan kuantitatif dengan pendekatan quasi experimental dan desain penelitian non equivalent control group design. Populasi anak usia dini kelompok B di RA Al Khodijah Purworejo Kecamatan Ngunut Kabupaten Tulungagung tahun pelajaran 2019/2020 yang terdiri dari kelompok $B_{1}$ sejumlah 30 anak dan kelompok $B_{2}$ sejumlah 30 anak. Sampel diambil dengan teknik purposive sampling sejumlah 30 anak. Variabel independen media audio visual dan alat peraga edukatif, variabel dependen pengembangan bahasa anak. Data diambil dengan lembar observasi pengembangan bahasa anak, kemudian dianalisis dengan uji paired sample $t$ test dan independent sample $t$ test.

Hasil dari penelitian didapatkan: 1) Ada pengaruh media pembelajaran audio visual terhadap hasil pengembangan bahasa anak kelas B di RA Al Khodijah Purworejo Ngunut Tulungagung. Hal tersebut ditunjukkan dari uji paired t test pengembangan bahasa anak antara sebelum dan sesudah pembelajaran media audio visual didapatkan $p$ value $0,000<$ 0,05. 2) Ada pengaruh alat peraga edukatif terhadap hasil pengembangan bahasa anak kelas B di RA Al Khodijah Purworejo Ngunut Tulungagung. Hal tersebut ditunjukkan dari uji paired $\mathrm{t}$ test pengembangan bahasa anak antara sebelum dan sesudah pembelajaran dengan alat peraga edukatif didapatkan $p$ value $0,000<0,05$. 3) Ada perbedaan pengaruh media pembelajaran audio visual dan alat peraga edukatif terhadap hasil pengembangan bahasa anak kelas B di RA Al Khodijah Purworejo Ngunut Tulungagung. Hal tersebut ditunjukkan dari uji independen $t$ test pengaruh media pembelajaran audio visual dan alat peraga edukatif terhadap hasil pengembangan bahasa anak didapatkan $\mathrm{p}$ value $0,004<0,05$.
\end{abstract}

Kata kunci : Media Audio Visual, Alat Peraga Edukatif, Pengembangan Bahasa Anak 



\begin{abstract}
The research in this thesis is motivated that the use of appropriate learning media can stimulate early childhood development. The selection and use of appropriate learning media can stimulate early childhood development in RA Al Khodijah Purworejo, Ngunut District, Tulungagung Regency. Audio visual media provides sound and moving images so that it can attract children's interest in learning and influence children's language intelligence. While learning by using APE will facilitate and provide opportunities for children to imagine, think creatively, create something new and find various alternatives in solving problems.

Researchers used a quantitative approach with a quasi-experimental approach and a non equivalent control group design research design. The population of early age group $B$ in RA Al Khodijah Purworejo, Ngunut Subdistrict, Tulungagung Regency in 2019/2020 consisted of B1 groups of 30 children and B2 groups of 30 children. Samples were taken with a purposive sampling technique of 30 children. The independent variable is audio visual media and educational teaching aids, the dependent variable is children's language development. Data was taken with an observation sheet of children's language development, then analyzed with paired sample t test and independent sample t test.

The results of the study found: 1) There is an influence of audio-visual learning media on the results of language development in grade B children at RA Al Khodijah Purworejo Ngunut Tulungagung. This is indicated by the paired t test for children's language development between before and after learning audio-visual media p value 0,000<0.05. 2) There is an influence of educational teaching aids on the language development results of class B children in RA Al Khodijah Purworejo Ngunut Tulungagung. This is indicated by the paired t test for children's language development between before and after learning with educational teaching aids $p$ value of $0,000<0.05$. 3) There is a difference in the influence of audio visual learning media and educational teaching aids on the language development results of class $B$ children in RA Al Khodijah Purworejo Ngunut Tulungagung. This is indicated by the independent $t$ test of the effect of audio visual learning media and educational teaching aids on the results of children's language development, $p$ value 0.004 $<0.05$.
\end{abstract}

Keywords: Audio Visual Media, Educational Aids, Children's Language Development 


\section{PENDAHULUAN}

Pendidikan anak usia dini di Indonesia mencakup beberapa jalur: pendidikan formal, pendididikan nonformal, dan pendidikan informal. Pendidikan formal yang terdiri dari pendidikan paling dasar: yaitu (taman kanak-kanak, Raudhatul Athfal atau bentuk lain yang sederajat), pendidikan nonformal yang terdiri dari: Kelompok Bermain, tempat Penitipan Anak atau bentuk lain yang sederajat, Pendidikan informal yang terdiri dari: pendidikan keluarga atau pendidikan yang diselenggarakan oleh lingkungan. Disinilah peran penting pemerintah dalam menggembangkan pendidikan anak usia dini di Indonesia.

Salah satu jenjang pendidikan pada anak usia 0-6 tahun adalah pendidikan anak usia dini yang menjadi tahap awal anak sebelum masuk ke dalam satuan pendidikan dasar. Sedangkan pendidikan anak usia dini adalah pemberian upaya untuk menstimulasi, membimbing, mengasuh, dan pemberian kegiatan pembelajaran yang akan menghasilkan kemampuan dan keterampilan pada anak (Mansur, 2011). Anak usia dini merupakan sekelompok anak yang berada dalam proses pertumbuhan dan perkembangan yang bersifat unik, artinya memiliki karakteristik pertumbuhan dan perkembangan fisik, motorik, kognitif, atau intelektual (daya fikir, daya cipta), sosial emosional, serta bahasa (Masitoh, 2016).

Kecerdasan linguistik perlu dikembangkan melalui pemberian stimulasi berupa media pembelajaran. Cara untuk menstimulasi bahasa perlu ada kegiatan yang menarik bagi anak sehingga bahasa dapat distimulasi dengan maksimal. Oleh karena itu seorang pendidik, baik guru maupun orang tua, memiliki peran yang sangat penting dalam menstimulasi perkembangan bahasa anak sehingga anak memiliki kecerdasan linguistik (bahasa) sebagaimana yang diharapkan. Namun demikian tidak semua anak usia dini memiliki kecerdasan linguistik sebagaimana yang diharapkan. Melalui media yang ada dan menarik, anak diharapkan dapat mengekpresikan apa yang dipikirkan tanpa merasa tertekan maupun takut sehingga apa yang dipikirkan akan mengalir begitu saja. Ketika ada pertanyaan yang muncul maupun ada yang mengganjal untuk dipertanyakan maka tanpa berpikir panjang anak akan langsung mengungkapkan apa yang dipikirkan.

Penggunaan media pembelajaran yang tepat dapat memberikan stimulasi perkembangan anak usia dini. Pemilihan dan penggunaan media pembelajaran yang tepat dapat menstimulasi perkembangan anak usia dini. Salah satu media yang dapat digunakan dalam pembelajaran anak usia dini adalah media audio visual. Media audio visual memberikan suara dan gambar yang bergerak sehingga dapat menarik minat anak dalam pembelajaran dan mempengaruhi kecerdasan bahasa anak. Media audio visual akan mempengaruhi perolehan kosa kata yang lebih banyak dan dimungkinkan anak akan cerdas dalam bahasa (Hanifah, 2014).

Selain itu kemampuan bahasa anak juga dapat dikembangkan melalui pembelajaran yang menarik dengan cara bermain dan menggunakan Alat Peraga Edukatif (APE). APE adalah semua alat bermain yang digunakan anak untuk memenuhi naluri bermain dan memiliki berbagai macam sifat seperti bungkar pasang, mengelompokkan, memadukan, merangkai, membentuk, atau menyusun sesuai bentuk utuhnya. Melalui APE siswa mudah menerima tujuan pembelajaran dan dapat memecahkan masalah dalam proses pembelajaran. Pembelajaran dengan menggunakan APE diharapkan anak dapat meningkatkan kemampuan lingustik yang ada dalam proses pembelajaran sehingga anak dapat mengoptimalkan aspek perkembangannya (Rolina, 2012). 
APE mempunyai peranan yang penting untuk mengembangkan aspek pada diri anak, sebab dunia anak ialah dunia bermain. Pembelajaran menggunakan APE dapat memudahkan anak dalam memahami dan memecahkan sendiri masalah yang anak temukan pada proses bermain yang dilakukan (Yuniarti, 2014). Pembelajaran dengan menggunakan APE, maka akan mempermudah dan memberikan kesempatan pada anak untuk berimajinasi, berfikir kreatif, menciptakan sesuatu yang baru dan menemukan berbagai alternatif dalam pemecahan masalah. Bahan alam merupakan salah satu media yang dapat digunakan untuk menyampaikan isi ataupun informasi yang hendak disampaikan kepada anak didik guna mengembangkan kreativitasnya. Bahan alam merupakan bahan yang langsung diperoleh dari alam, kemudian diolah menjadi suatu karya yang bermutu.

Hasil ovservasi di Kelas B RA Al Khodijah Purworejo menunjukkan bahwa mayoritas anak belum memiliki kecerdasan bahasa sebagaimana yang diharapkan. Terlihat dari banyaknya anak yang masih kesulitan mengajukan pertanyaan, dalam menjawab pertanyaan anak cenderung diam. Kondisi tersebut disebabkan karena kegiatan pembelajaran cenderung searah, guru cenderung hanya melakukan ceramah. Media yang digunakan guru hanya berupa buku yang berisi tugas-tugas yang harus dikerjakan oleh anak yang berkaitan dengan baca tulis hitung dan gambar sehingga wajar jika kecerdasan linguistik anak tidak berkembang sesuai dengan yang diharapkan.

\section{LANDASAN TEORI \\ Media Pembelajaran}

Media adalah sumber belajar sehingga secara luas media pembelajaran dapat diartikan dengan manusia, benda ataupun peristiwa yang memungkinkan siswa memperoleh pengetahuan serta keterampilan. Media merupakan alat bantu yang dapat berupa apa saja yang dapat dijadikan sebagai penyalur pesan guna mencapai tujuan pembelajaran. Kehadiran media mempunyai arti yang cukup penting dalam proses belajar mengajar, karena dalam kegiatan tersebut ketidak jelasan bahan yang disampaikan dapat dibantu dengan menghadirkan media sebagai perantara (Ainina, 2014).

\section{Media Audio Visual}

Media audio visual adalah suatu media yang digunakan dalam kegiatan pembelajaran dengan melibatkan pendengaran dan penglihatan sekaligus dalam satu proses atau kegiatan. Pesan dan informasi yang dapat disalurkan melalui media ini dapat berupa pesan verbal dan nonverbal yang mengandalkan baik penglihatan maupun pendengaran (Asyhar, 2011).. Dalam penelitian ini media audio visual adalah media penyalur pesan dengan memanfaatkan indera pendengaran dan penglihatan karena kombinasi antara gambar dan suara.

\section{Alat Peraga Edukatif}

Alat Peraga edukatif (APE) merupakan alat peraga yang dapat memberikan fungsi permainan secara optimal bagi tumbuh kembang anak, dimana melalui alat permainan ini anak dapat mengembangkan kemampuan fisiknya, bahasa, kemampuan kognitif, dan adaptasi sosial. Guru dan orang tua dalam memilih peraga edukatif harus memperhatikan kelayakan dan keamanan mainan tersebut, syarat-syarat yang perlu diperhatikan adalah desain mudah dan sederhana, multifungsi, menarik, berukuran besar, awet dan sesuai 
kebutuhan, mendorong anak untuk bermain bersama, mengembangkan daya fantasi (Yuniarti, 2014).

\section{Pengembangan Bahasa}

Bahasa anak usia dini adalah rangkaian bunyi yang melambangkan pikiran, perasaan serta sikap manusia yang digunakan untuk menyampaikan keinginan, pikiran, harapan, permintaan, dan kepentingan pribadi lainnya" (Suhartono, 2005). Aspek perkembangan bahasa merupakan alat untuk berkomunikasi, mengekspresikan perasaan dan pikiran. Perkembangan bahasa dimulai sejak dini dimulai dari lingkungannya, baik keluarga, masyarakat, maupun sekolah. Pengembangan kemampuan berbahasa bagi anak usia dini bertujuan agar anak mampu berkomunikasi secara lisan dengan lingkungannya (Permendiknas No. 137, 2014).

\section{Anak Usia Dini}

Anak usia dini adalah anak yang baru dilahirkan sampai usia 6 tahun. Usia ini merupakan usia yang sangat menentukan pembentukan karakter dan kepribadian anak. Usia dini merupakan usia dimana anak mengalami pertumbuhan dan perkembangan yang pesat. Usia dini disebut dengan usia emas (golden age). Makanan yang bergizi dan seimbang serta stimulasi yang intensif sangat dibutuhkan untuk pertumbuhan dan perkembangan tersebut (Yuliani, 2009).

\section{HIPOTESIS PENELITIAN}

Hipotesis dalam penelitian ini adalah:

$\mathrm{H}_{1}$ : Terdapat perbedaan peningkatan kemampuan bahasa anak kelas B di RA Al Khodijah Purworejo Kecamatan Ngunut Kabupaten Tulungagung sebelum dan sesudah mengikuti pembelajaran dengan media audio visual

$\mathrm{H}_{2}$ : Terdapat perbedaan peningkatan kemampuan bahasa anak kelas B di RA Al Khodijah Purworejo Kecamatan Ngunut Kabupaten Tulungagung sebelum dan sesudah mengikuti pembelajaran dengan alat peraga edukatif

$\mathrm{H}_{3}$ : Terdapat perbedaan peningkatan kemampuan bahasa anak kelas B di RA Al Khodijah Purworejo Kecamatan Ngunut Kabupaten Tulungagung antara yang diberi perlakuan media audio visual dengan alat permainan edukatif

\section{KERANGKA KONSEPTUAL}

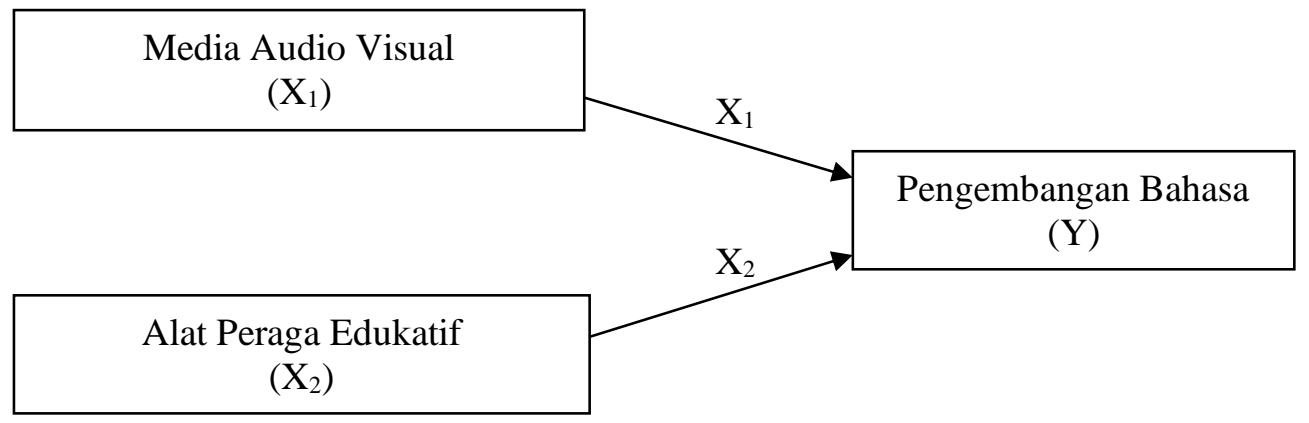




\section{Gambar 1}

\section{Kerangka konseptual penelitian}

\section{METODE PENELITIAN}

\section{Variabel}

a. Variabel Bebas (Independent Variable)

Dalam penelitian ini yang menjadi variabel bebas adalah:

X1 : Media audio visual

$\mathrm{X} 2$ : Alat peraga edukatif

b. Variabel Terikat (Dependent Variable)

Variabel terikat dalam penelitian ini adalah kemampuan bahawa yang diberi notasi Y.

\section{Skala Pengukuran}

Skala pengukuran yang dipakai adalah skala ordinal yaitu data hasil pengamatan diklasifikasikan ke dalam kategori-kategori, dan diantara kategori ada suatu urutan.

\section{Populasi, Sampling Dan Sampel Penelitian}

\section{Populasi}

Populasi dalam penelitian ini adalah anak usia dini kelompok B di RA Al Khodijah Purworejo Kecamatan Ngunut Kabupaten Tulungagung tahun pelajaran 2019/2020 yang terdiri dari kelompok $\mathrm{B}_{1}$ sebanyak 30 anak dan kelompok $\mathrm{B}_{2}$ sebanyak 30 anak sehingga jumlah total siswa sebanyak 60 anak.

\section{Sampling}

Metode pengambilan sampel pada penelitian ini ialah menggunakan metode purposive sampling. purposive sampling sendiri ialah pengambilan sampel yang berdasarkan atas pertimbangan-pertimbangan tertentu dari peneliti.

Perlakuan terhadap sampel adalah sebagai berikut:

a. Melakukan pre test untuk mencari rangking kemampuan bahasa anak kelompok $\mathrm{B}_{1}$ dan $B_{2}$ RA Al Khadijah Purworejo Kecamatan Ngunut Kabupaten Tulungagung.

b. Setelah didapatkan rangking maka akan dipilih kelompok media audio visual dan kelompok alat permainan edukatif dengan cara mengambil siswa dengan hasil pre test rangking $1-15$

c. Kelompok yang mengikuti pembelajaran dengan media audio visual diambil dari kelompok $\mathrm{B}_{1}$ rangking 1-15

d. Kelompok yang mengikuti pembelajaran dengan alat permainan edukatif diambil dari kelompok $\mathrm{B}_{2}$ rangking 1-15

\section{Sampel Penelitian}

Jumlah sampel adalah 30 siswa RA Al Khadijah Purworejo Ngunut Tulungagung kelompok B

\section{Instrumen Penelitian}


Instrumen yang digunakan untuk mengetahui pengembangan bahasa anak adalah dengan lembar observasi pengembangan bahasa anak

\section{Analisis Data}

Uji hipotesis pada penelitian ini menggunakan uji beda (paired sample t-test) pada hipotesis 1 dan 2, dan menggunakan uji beda (independent sample t-test) pada hipotesis 3. Pada uji ini menggunakan sebuah kelompok sampel dengan subyek yang sama namun mengalami dua perlakuan atau pengukuran yang berbeda.

Pengambilan keputusan dapat dilakukan dengan menyoroti nilai signifikansi. Untuk mengetahui apakah perbedaan rata-rata kedua sampel tersebut signifikan atau tidak maka dilakukan kriteria pengujian dengan rumusan hipotesis :

a. Jika Sig. > 0,05 maka $\mathrm{H}_{0}$ diterima.

b. Jika Sig. $<0,05$ maka $\mathrm{H}_{0}$ ditolak.

\section{HASIL DAN ANALISIS DATA}

\section{Hasil Uji Paired T Test}

Tabel 1 Uji paired t test

\begin{tabular}{|c|c|c|c|c|c|c|c|c|c|}
\hline \multicolumn{10}{|c|}{ Paired Differences } \\
\hline & & \multirow[b]{2}{*}{ Mean } & \multirow{2}{*}{$\begin{array}{c}\text { Std. } \\
\text { Deviation }\end{array}$} & \multicolumn{3}{|c|}{$\begin{array}{cc} & 95 \% \text { Confidence Interval of } \\
\text { Std. Error } & \text { the Difference }\end{array}$} & \multirow[b]{2}{*}{$\mathrm{t}$} & \multirow[b]{2}{*}{$\mathrm{df}$} & \multirow{2}{*}{$\begin{array}{l}\text { Sig. }(2- \\
\text { tailed) }\end{array}$} \\
\hline & & & & Mean & Lower & Upper & & & \\
\hline \multirow[t]{2}{*}{ Pair 1} & Pretest Media & & & & & & & & \\
\hline & $\begin{array}{l}\text { Audio Visual - } \\
\text { Posttest Media } \\
\text { Audio Visual }\end{array}$ & -8.86667 & 63994 & .16523 & -9.22105 & -8.51228 & -53.662 & 14 & .000 \\
\hline \multirow[t]{2}{*}{ Pair 2} & Pretest Alat & & & & & & & & \\
\hline & $\begin{array}{l}\text { Peraga Edukatif } \\
\text { - Posttest Alat } \\
\text { Peraga Edukatif }\end{array}$ & -9.86667 & 1.06010 & .27372 & -10.45373 & -9.27960 & -36.047 & 14 & .000 \\
\hline
\end{tabular}

Sumber: output SPSS

Uji paired t test tersebut untuk menjawab hipotesis dari rumusan masalah 1 . Berdasarkan uji paired t test pengembangan bahasa anak antara sebelum dan sesudah pembelajaran media audio visual didapatkan $p$ value $0,000<0,05$, maka $\mathrm{H}_{0}$ ditolak dan $\mathrm{H}_{1}$ diterima, artinya ada pengaruh media pembelajaran audio visual terhadap hasil pengembangan bahasa anak kelas B di RA Al Khodijah Purworejo Kecamatan Ngunut Kabupaten Tulungagung.

Uji paired $t$ test tersebut juga untuk menjawab hipotesis dari rumusan masalah 2. Berdasarkan uji paired t test pengembangan bahasa anak antara sebelum dan sesudah pembelajaran dengan alat peraga edukatif didapatkan $p$ value $0,000<0,05$, maka $\mathrm{H}_{0}$ ditolak dan $\mathrm{H}_{1}$ diterima, artinya ada pengaruh alat peraga edukatif terhadap hasil pengembangan bahasa anak kelas B di RA Al Khodijah Purworejo Kecamatan Ngunut Kabupaten Tulungagung.

\section{Uji independent t test}


Untuk mengetahui perbedaan pengaruh media pembelajaran audio visual dan alat peraga edukatif terhadap hasil pengembangan bahasa anak digunakan uji statistik independen $t$ test. Dengan menggunakan software SPSS, diperoleh hasil analisis independen $\mathrm{t}$ test sebagai berikut:

Tabel 2 Uji independent t test

\begin{tabular}{|c|c|c|c|c|c|c|c|c|c|c|}
\hline & & \multicolumn{3}{|c|}{$\begin{array}{c}\text { Levene's Test } \\
\text { for Equality of } \\
\text { Variances }\end{array}$} & & \multicolumn{3}{|c|}{ t-test for Equality of Means } & \multicolumn{2}{|c|}{$\begin{array}{l}95 \% \text { Confidence } \\
\text { Interval of the } \\
\text { Difference }\end{array}$} \\
\hline & & $\mathrm{F}$ & Sig. & $\mathrm{t}$ & df & tailed) & Difference & Difference & Lower & Upper \\
\hline \multirow[t]{2}{*}{ Gain } & $\begin{array}{l}\text { Equal } \\
\text { variances } \\
\text { assumed }\end{array}$ & 1.218 & .279 & -3.128 & 28 & .004 & -1.00000 & .31972 & -1.65492 & -.34508 \\
\hline & $\begin{array}{l}\text { Equal } \\
\text { variances not } \\
\text { assumed }\end{array}$ & & & -3.128 & 23.007 & .005 & -1.00000 & .31972 & -1.66138 & -.33862 \\
\hline
\end{tabular}

Sumber: output SPSS

Uji independent $\mathrm{t}$ test tersebut untuk menjawab hipotesis dari rumusan masalah 3. Berdasarkan uji independen t test pengaruh media pembelajaran audio visual dan alat peraga edukatif terhadap hasil pengembangan bahasa anak didapatkan $\mathrm{p}$ value $0,004<0,05$, maka $\mathrm{H}_{0}$ ditolak dan $\mathrm{H}_{1}$ diterima, artinya ada perbedaan pengaruh media pembelajaran audio visual dan alat peraga edukatif terhadap hasil pengembangan bahasa anak kelas B di RA Al Khodijah Purworejo Kecamatan Ngunut Kabupaten Tulungagung.

\section{PEMBAHASAN \\ Pengaruh media pembelajaran audio visual terhadap hasil pengembangan bahasa anak kelas B di RA Al Khodijah Purworejo Ngunut Tulungagung}

Hasil penelitian uji paired t test pengembangan bahasa anak antara sebelum dan sesudah pembelajaran media audio visual didapatkan $p$ value $0,000<0,05$, maka $\mathrm{H}_{0}$ ditolak dan $\mathrm{H}_{1}$ diterima, artinya ada pengaruh media pembelajaran audio visual terhadap hasil pengembangan bahasa anak kelas B di RA Al Khodijah Purworejo Ngunut Tulungagung.

Perkembangan bahasa untuk anak usia dini meliputi empat pengembangan yaitu mendengarkan, berbicara, membaca dan menulis. Pengembangan tersebut harus dilakukan seimbang agar memperoleh pengembangan membaca dan menulis yang optimal. Perkembangan bahasa untuk anak taman kanak-kanak berdasarkan acuan standar pendidikan anak usia dini no. 58 tahun 2009, mengembangkan tiga aspek yaitu menerima bahasa, mengungkapkan bahasa, dan keaksaraan. Kemampuan bahasa merupakan kesanggupan, kecakapan, kekayaan ucapan pikiran dan perasaan manusia melalui bunyi yang arbiter, digunakan untuk bekerjasama, berinteraksi, dan mengidentifikasi diri dalam percakapan yang baik. 
Kemampuan berbahasa sangat dekat sekali hubungannya dengan pengaruh intelektual atau kognisi. Seorang anak semakin lama akan semakin memahami tingkatan bahasa, mulai dari yang sangat sederhana sampai ke yang kompleks. Keterampilan berbahasanya juga akan berubah dan berkembang. Keterampilan awal yaitu listening (mendengarkan). Kemudian akan diikuti oleh keterampilan speaking (berbicara), reading (membaca) dan writing (menulis).

Fungsi bahasa bagi anak usia dini ialah sebagai alat untuk mengembangkan keterampilan intelektual dan keterampilan dasar anak. Secara khusus bahwa fungsi bahasa bagi anak usia dini adalah untuk mengembangkan ekspresi atau perasaan, imajinasi, dan pikiran.

Kemampuan bahasa yang dimiliki anak akan menjadi modal utama dalam berkomunikasi terhadap teman-temannya, orangtuanya, gurunya dan sebagainya. Setidaknya, sebelum memasuki sekolah formal anak memiliki bahasa "ibu". Bahasa yang dimiliki oleh anak TK bersifat egosentris dan self ekspressive yaitu banyak hal yang masih dikaitkan dengan dirinya sendiri. Sementara itu, kemampuan bahasa yang dimiliki anak menjadi salah satu tolak ukur kecerdasannya. Pada saat ini anak mulai menguasai kemampuan dalam berbahasa, namun mereka didorong lebih banyak belajar untuk mencapai kemampuan bahasa orang dewasa.

Pengukuran pengembangan bahasa anak di RA Al Khodijah Purworejo Ngunut Tulungagung dilakukan dua kali, yaitu sebelum dan sesudah pembelajaran dengan media audio visual. Pre test dilakukan untuk mengetahui kemampuan awal pengembangan bahasa anak. Pre test dilakukan kepada siswa kleompok B1 dan B2, kemudian hasilnya dirangking dan dikelompokkan untuk jenis media pembelajaran yang akan diterapkan. Perserta pembelajaran media audio visual terdiri dari rangking pretest 1-7 kelompok B1 dan 8-15 kelompok B2.

Pembelajaran media audio visual dilaksanakan 3 kali pertemuan dengan setiap pertemuan berbeda jenis materinya yaitu pada tema pekerjaan: guru, polisi dan petani. Kegiatan guru pada pertemuan pertama adalah: guru menyiapkan RPPH sebelum kegiatan, guru menyiapkan media audio visual sebelum kegiatan berlangsung, guru memberi tahu tentang kegiatan yang ingin dilakukan, guru melaksanakan pembelajaran dengan media audio visual, guru mengawasi/ mendampingi anak saat kegiatan berlangsung, dan guru menutup kegiatan pembelajaran.

Kegiatan siswa pada pertemuan pertama ini adalah: siswa menyiapkan diri dalam belajar, siswa memperhatikan dan menyiapkan diri dalam belajar, siswa mendengarkan, menyaksikan video pembelajaran, siswa mengikuti kegiatan yang berlangsung, berdoa, mengucapkan salam. Pertemuan kedua dan ketiga sama dengan pertemuan pertama dalam pelaksanaannya. Bedanya dalam pertemuan kedua dan ketiga adalah pada jenis materi yang disampaikan.

Media audio-visual adalah media kombinasi antara audio dan visual yang diciptakan sendiri seperti slide yang dikombinasikan dengan kaset audio. Pendapat lain menjelaskan bahwa media audio visual adalah media intruksional modern yang sesuai dengan perkembangan zaman (kemajuan ilmu pengetahuan dan teknologi), meliputi media yang dilihat dan didengar. Sementara itu Sudjana dan Rivai mengungkapkan bahwa media audio visual adalah "sejumlah peralatan yang dipakai oleh para guru dalam menyampaikan konsep, gagasan dan pengalaman yang ditangkap oleh indera pandang dan pendengaran”. 
Penggunaan media audio visual dapat mempertinggi perhatian anak dengan tampilan yang menarik. Selain itu, anak akan takut ketinggalan jalannya video tersebut jika melewatkan dengan mengalihkan konsentrasi dan perhatian. Media audio visual yang menampilkan realitas materi dapat memberikan pengalaman nyata pada siswa saat mempelajarinya sehingga mendorong adanya aktivitas diri.

Terdapat beberapa kelebihan dan kekurangan penggunaan media audio visual dalam pembelajaran. Kelebihan dan kekurangan media audio visual yaitu: Kelebihan menggunakan media audio visual yaitu dapat memperjelas penyajian pesan agar tidak terlalu bersifat verbalistis (dalam bentuk kata-kata, tertulis atau lisan), dapat mengatasi keterbatasan ruang, waktu dan daya indera, seperti: objek yang terlalu besar digantikan dengan realitas, gambar, film bingkai, film atau model, serta media audio-visual bisa berperan dalam pembelajaran tutorial. Selain itu pemakaiannya tidak membosankan, hasilnya lebih mudah untuk dipahami, dan informasi yang diterima lebih jelas dan cepat dimengerti. Mengajar akan lebih bervariasi, tidak sematamata komunikasi verbal melalui penuturan kata-kata oleh guru. Sehingga siswa tidak bosan dan guru tidak kehabisan tenaga apalagi bila guru mengajar untuk setiap jam pelajaran.

Media audio visual digunakan dalam upaya peningkatan atau mempertinggi mutu proses kegiatan belajar mengajar. Agar dapat mengoptimalkan peranan media pembelajaran yang digunakan untuk mencapai tujuan pembelajaran, maka harus diperhatikan prinsipprinsip penggunaannya antara lain: 1) Penggunaan media pembelajaran hendaknya dipandang sebagai bagian integral dari suatu sistem pengajaran, 2) Media pembelajaran hendaknya dipandang sebagai sumber belajar yang digunakan dalam pemecahan masalah yang dihadapi dalam proses belajar mengajar, 3) Guru harus benar-benar menguasai teknik dari media pembelajaran yang digunakan, 4) Guru harus memperhitungkan untung ruginya penggunaan media pembelajaran, 5) Penggunaan media pengajaran harus diorganisir secara sistematis bukan sembarangan menggunakannya dan 6) Jika suatu pokok bahasan memerlukan lebih dari satu macam media maka guru dapat memanfaatkan multimedia yang memperlancar proses belajar mengajar.

\section{Pengaruh alat peraga edukatif terhadap hasil pengembangan bahasa anak kelas $B$ di RA Al Khodijah Purworejo Ngunut Tulungagung}

Hasil penelitian uji paired test pengembangan bahasa anak antara sebelum dan sesudah pembelajaran dengan alat peraga edukatif didapatkan $p$ value $0,000<0,05$, maka $\mathrm{H}_{0}$ ditolak dan $\mathrm{H}_{1}$ diterima, artinya ada pengaruh alat peraga edukatif terhadap hasil pengembangan bahasa anak kelas B di RA Al Khodijah Purworejo Ngunut Tulungagung.

Pengembangan bahasa Anak Usia Dini (AUD) adalah upaya guru dalam rangka pencapaian tujuan pendidikan AUD dalam mengembangkan bahasanya, yakni yang lebih difokuskan pada ruang lingkup pengembangan bahasa yang tertuang dalam Satuan Pendidikan TK. Untuk dapat mencapai tujuan tersebut, pemahaman guru tentang berbahasa khususnya menyimak dan berbicara perlulah dipahami secara baik. Anak usia 4 tahun perkembangan kosaskata anak mencapai 4.000-6.000 kata dan berbicara dalam kalimat 5-6 kata. Usia 5 tahun perbendaharaan kata terus bertambah mencapai 5.000 sampai 8.000 kata. Kalimat yang dipakaipun semakin kompleks. 
Pengukuran pengembangan bahasa anak di RA Al Khodijah Purworejo Ngunut Tulungagung dilakukan dua kali, yaitu sebelum dan sesudah pembelajaran dengan alat peraga edukatif. Pre test dilakukan untuk mengetahui kemampuan awal pengembangan bahasa anak siswa. Pre test dilakukan kepada siswa kleompok B1 dan B2, kemudian hasilnya dirangking dan dikelompokkan untuk jenis media yang akan digunakan. Perserta pembelajaran media alat peraga edukatif terdiri dari rangking pretest 1-7 kelompok B2 dan 8-15 kelompok B1.

Pembelajaran dengan alat peraga edukatif dilaksanakan 3 kali pertemuan dengan setiap pertemuan berbeda jenis materinya yaitu tema pekerjaan: guru, polisi, petani. Kegiatan guru pada pertemuan pertama adalah: guru menyiapkan RPPH sebelum kegiatan, guru menyiapkan alat permainan edukatif (APE) berupa boneka jari sebelum kegiatan berlangsung, guru memberi tahu tentang kegiatan yang ingin dilakukan, guru memberi arahan atau peraturan sebelum kegiatan, guru memberi contoh langkah-lahkah kegiatan yang akan dilakukan, guru mengawasi/ mendampingi anak saat kegiatan berlangsung.

Kegiatan siswa pada pertemuan pertama ini adalah: siswa menyiapkan diri dalam belajar, siswa memperhatikan dan menyiapkan diri dalam belajar, siswa mendengarkan, siswa memperhatikan arahan atau peraturan sebelum kegiatan, siswa memperhatikan contoh langkah-lahkah kegiatan yang akan dilakukan, siswa mengikuti kegiatan yang berlangsung.

Pertemuan kedua dan ketiga sama dengan pertemuan pertama dalam pelaksanaannya. Bedanya dalam pertemuan kedua dan ketiga adalah pada materi yang disampaikan. Pertemyan kedua materi pekerjaan polisi dan pertemuan ketiga materi pekerjaan petani.

Alat permainan edukatif merupakan permainan edukatif adalah semua bentuk permainan yang dirancang untuk memberikan pengalaman pendidikan atau pengalaman belajar kepada para pemainnya. Sedangkan, Syamsuardi mengatakan bahwa "Alat permainan edukatif adalah alat yang dirancang khusus sebagai alat untuk bantu belajar dan dapat mengoptimalkan perkembangan anak, disesuaikan dengan usia dan tingkat perkembangannya"

Sementara itu, bahan alam merupakan salah satu APE yang dapat digunakan untuk menyampaikan isi atau informasi yang hendak disampaikan kepada anak didik guna mengembangkan kreativitasnya. Menurut Sudjana "bahan alam adalah bahan yang diperoleh dari alam untuk membuat suatu produk atau karya. Bahan alam dapat dimanfaatkan sebagai media dalam belajar." Dengan kata lain bahan alam adalah bahan yang diperoleh langsung dari alam yang dapat diolah menjadi barang-barang yang bermanfaat.

Fungsi alat permainan edukatif di TK adalah: pertama alat untuk membantu dan mendukung proses pembelajaran anak TK agar lebih baik, menarik dan jelas. Kedua, dapat mengembangkan seluruh aspek perkembangan anak. Ketiga, memberi kesempatan pada anak TK memperoleh pengetahuan baru dan memperkaya pengalamannya dengan berbagai alat permainan. Keempat memberi kesempatan pada anak TK untuk mengenal lingkungan dan mengajarkan pada anak untuk mengetahuai kekuatan diriya.

Manfaat lain Alat Permainan Edukatif (APE) adalah sebagai berikut: 1). APE untuk pengembangan fisik motorik Anak usia dini terutama usia taman kanak-kanak adalah anak yang selalu aktif. Karenanya, sebagian besar alat bermain diperuntukkan bagi pengembangan koordinasi gerakan otot kasar. Penyediaan peralatan untuk melatih gerakan otot kasar, misalnya kegiatan naik turun tangga, meluncur, akrobatik, memanjat, berayun dengan papan keseimbangan dan sebagainya. 2). APE untuk pengembangan kognitif Kemampuan kognitif 
yang dapat dikembangkan melalui kegiatan bermain diantaranya, kemampuan mengenai sesuatu, mengingat barang, menghitung jumlah dan memberi penilaian. Kegiatan bermain dilakukan dengan mengamati, seperti melihat bentuk, warna dan ukuran. Sedangkan kegiatan mendengar dilakukan dengan mendengar bunyi, suara dan nada. Bahan dan peralatan yang dibutuhkan untuk mengembangkan aspek kognitif di antaranya papan pasak kecil, papan pasak berjenjang, papan tongkat, warna, menara gelang bujur sangkar, balok ukur, papan hitung dan lainnya. 3). APE untuk pengembangan kreatifitas. Ciri-ciri anak kreatif adalah kelenturan, kepekaan, penggunaan daya imajinasi, ketersediaan mengambil resiko dan menjadikan diri sendiri sebagai sumber dan pengalaman. APE semacam tanah liat, cat, krayon, kertas, balok-balok, air, dan pasir dapat mendorong anak untuk mencoba cara-cara baru dan dengan sendirinya akan meningkatkan kreatifitas anak.

APE yang akan digunakan sebagai media bermain hendaknya memenuhi persyaratan berikut ini: a) mengandung nilai pendidikan, b) aman, dalam arti tidak membahayakan anak, c) menarik bagi anak, baik dari segi warna maupun bentuk, d) sesuai dengan minat dan taraf perkembangan anak, e) sederhana, murah, dan mudah diperoleh, f) awet, mudah pemeliharaannya, dan tidak mudah rusak, g) ukuran dan bentuknya sesuai dengan usia anak, dan h) berfungsi mengembangkan kemampuan anak.

APE yang diterapkan oleh peneliti pada proses belajar mengajar dapat membuat peserta didik lebih kreatif, karena dengan APE peserta didik bisa mengetahui media-media, kemudian bisa dijadikan alat permaianan yang menyenangkan dan memberi wawasan lebih bagi peserta didik. Selain itu, peserta didik diharapkan untuk lebih aktif dalam kegiatan pembelajaran agar peserta didik lebih menikmati lagi proses pembelajaran yang diberikan oleh dewan guru dengan media atau APE yang menyenangkan bagi anak seperti APE bahan alam. Dengan adanya APE yang menyenangkan diharapakan membuat suasana pembelajaran didalam kelas lebih menarik dan dapat meningkatkan kreativitas peserta didik.

\section{Perbedaan pengaruh media pembelajaran audio visual dan alat peraga edukatif terhadap hasil pengembangan bahasa anak kelas B di RA Al Khodijah Purworejo Ngunut Tulungagung}

Uji independen $t$ test pengaruh media pembelajaran audio visual dan alat peraga edukatif terhadap hasil pengembangan bahasa anak didapatkan $\mathrm{p}$ value $0,004<0,05$, maka $\mathrm{H}_{0}$ ditolak dan $\mathrm{H}_{1}$ diterima, artinya ada perbedaan pengaruh media pembelajaran audio visual dan alat peraga edukatif terhadap hasil pengembangan bahasa anak kelas B di RA Al Khodijah Purworejo Ngunut Tulungagung.

Hasil data perbedaan pengembangan bahasa anak di RA Al Khodijah Purworejo Ngunut Tulungagung antara pretest dan posttest Kelompok Media Audio Visual diperoleh nilai mimimum $=8$, nilai maksimum $=10$, mean $=8,87$ median $=9$, modus $=9$ dan standar deviasi $=0,64$. Sedangkan hasil data perbedaan pengembangan bahasa anak di RA Al Khodijah Purworejo Ngunut Tulungagung antara pretest dan posttest Kelompok Alat Peraga Edukatif diperoleh nilai mimimum $=8$, nilai maksimum $=12$, mean $=9,87$ median $=10$, modus $=10$ dan standar deviasi $=1,06$.

Berdasarkan hasil data tersebut menunjukkan bahasa ada perbedaan mean antara media audio visual dan alat peraga edukatif, dimana mean alat peraga edukatif lebih tinggi. Hal ini menunjukkan bahwa pembelajaran dengan alat peraga edukatif lebih baik dalam 
meningkatkan pengembangan bahasa anak usia dini di RA Al Khodijah Purworejo Ngunut Tulungagung.

Media adalah perantara atau pengantar pesan dari pengirim ke penerima pesan. Dalam proses belajar mengajar kehadiran media mempunyai arti yang cukup penting karena dalam kegiatan tersebut ketidakjelasan bahan yang disampaikan dapat dibantu dengan menghadirkan media sebagai perantara. Kerumitan bahan yang akan disampaikan kepada anak didik dapat disederhanakan dengan bantuan media. Media dapat mewakili kata-kata atau kalimat tertentu yang sulit disampaikan. Bahkan keabstrakan bahan dapat dikonkritkan dengan kehadiran media. Dengan demikian, anak didik lebih mudah mencerna bahan daripada tanpa batuan media.

Pengalaman dibangun dari tingkat konkrit menuju ke tingkat abstrak. Pada tingkat konkrit seseorang belajar dari pengalaman nyata sebagai medianya. Pengalaman ini harus dilakukan langsung oleh anak melalui berbagai aktivitas yang pada akhirnya akan membentuk pemahaman baik konsep, prinsip, norma, maupun keterampilan, kemudian meningkat pada pengalaman yang lebih tinggi menuju ke puncak kerucut yaitu bentuk pengalaman belajar yang bersifat abstrak. Kerucut pengalaman membentangkan pengalaman konkrit sampai abstrak yang dilalui anak sesuai dengan tahapan perkembangannya:

Adapun manfaat penggunaan media dalam pembelajaran adalah: Penyampaian materi dapat diseragamkan; Proses pembelajaran menjadi lebih jelas dan menarik; Proses pembelajaran menjadi lebih interaktif; Efisiensi waktu dan tenaga; Meningkatkan kualitas hasil belajar siswa; Media memungkinkan proses belajar dapat dilakukan di mana saja dan kapan saja; Media dapat menumbuhkan sikap positif siswa terhadap materi dan proses belajar; dan Mengubah peran guru kearah yang lebih positif dan produktif.

Jenis-jenis media pendidikan yang biasa digunakan dalam proses belajar mengajar sebagai berikut; Pertama, media grafis seperti gambar, foto, grafik, bagan atau diagram, poster kartun, komik dan lain-lain. Media grafis sering juga disebut media dua dimensi, yakni media yang mempunyai ukuran panjang dan lebar. Kedua media tiga dimensi yaitu dalam bentuk model seperti model padat (solit model), model penampang, model susun, model kerja, mock up, dan lain-lain. Ketiga, model proyeksi spserti slide, film strips, film, penggunaan OHP dan lain-lain. Keempat, penggunaan lingkungan sebagai media pengajaran.

Setiap anak memiliki perkembangan dan pertumbuhan yang berbeda-beda antara satu dengan yang lainnya, terutama pada perkembangan bahasanya. Berbicara merupakan bentuk komunikasi secara lisan yang berfungsi untuk menyampaikan maksud dengan lancar, menggunakan kata-kata, dan menggunakan kalimat dengan jelas. Perkembangan bahasa anak usia 3-5 tahun sudah dapat berbicara dengan baik.

Perkembangan bahasa bagi anak usia dini berfungsi sebagai: a) alat untuk berkomunikasi dengan lingkungan, b) alat untuk mengembangkan keterampilan intelektual anak, c) alat untuk mengembangkan ekspresi anak, d) alat untuk menyatakan perasaan dan buah pikiran kepada orang lain. Fungsi bahasa bagi anak usia dini ialah sebagai alat untuk mengembangkan keterampilan intelektual dan keterampilan dasar anak. Secara khusus bahwa fungsi bahasa bagi anak usia dini adalah untuk mengembangkan ekspresi atau perasaan, imajinasi, dan pikiran.

Anak usia dini mempunyai kapasitas keterampilan berbahasa yang berbeda-beda. Pada saat anak usia dini mulai memperoleh bahasa, hal ini sangat penting untuk diketahui sebagai tolak ukur untuk mengetahui perkembangan bahasanya. Teori behaviorisme 
berangkat dari pemahaman bahwa stimulus yang dapat dilihat juga dapat menyebabkan adanya respon yang dapat dilihat. Pendapat lain mengungkapkan bahwa teori behavioristik adalah pembelajaran tidak lain daripada memberi stimulus $(S)$ atau rangsangan tertentu kepada anak yang kemudian mengakibatkan adanya reaksi atau respon (R) yang diharapkan sesuai dengan tujuan.

Salah satu ciri orang yang memiliki kecerdasan linguistik yaitu "mampu menggunakan kemampuan menulis secara efektif, memahami dan menerapkan aturan-aturan tata bahasa, ejaan, tanda baca, dan menggunakan kosakata efektif'. Secara sederhana ciriciri orang memiliki kecerdasan linguistik adalah "individu yang cerdas secara verballinguistik menonjol dalam berkata-kata, baik lisan maupun tertulis serta mampu mengekspresikannya secara proporsional".

Kemampuan bahasa yang dimiliki anak akan menjadi modal utama dalam berkomunikasi terhadap teman-temannya, orangtuanya, gurunya dan sebagainya. Setidaknya, sebelum memasuki sekolah formal anak memiliki bahasa "ibu". Bahasa yang dimiliki oleh anak TK bersifat egosentris dan self ekspressive yaitu banyak hal yang masih dikaitkan dengan dirinya sendiri. Sementara itu, kemampuan bahasa yang dimiliki anak menjadi salah satu tolak ukur kecerdasannya. Pada saat ini anak mulai menguasai kemampuan dalam berbahasa, namun mereka didorong lebih banyak belajar untuk mencapai kemampuan bahasa orang dewasa.

Hasil penelitian ini menunjukkan bahwa perkembangan bahasa dengan pembelajaran APE lebih tinggi peningkatannya dibandingkan dengan yang menggunakan media video. Hal ini diketahui dari hasil data perbedaan pengembangan bahasa anak di RA Al Khodijah Purworejo Ngunut Tulungagung antara pretest dan posttest Kelompok Media Audio Visual diperoleh nilai mimimum $=8$, nilai maksimum $=10$, mean $=8,87$ median $=9$, modus $=9$ dan standar deviasi $=0,64$. Sedangkan data perbedaan pengembangan bahasa anak di RA Al Khodijah Purworejo Ngunut Tulungagung antara pretest dan posttest Kelompok Alat Peraga Edukatif diperoleh nilai mimimum $=8$, nilai maksimum $=12$, mean $=9,87$ median $=10$, modus $=10$ dan standar deviasi $=1,06$.

Kemamuan bahasa dengan pembelajaran media APE tersebut dikarenakan APE yang diterapkan oleh peneliti pada proses belajar mengajar dapat membuat peserta didik lebih kreatif, karena dengan APE peserta didik bisa mengetahui media-media, kemudian bisa dijadikan alat permaianan yang menyenangkan dan memberi wawasan lebih bagi peserta didik. Selain itu, peserta didik diharapkan untuk lebih aktif dalam kegiatan pembelajaran agar peserta didik lebih menikmati lagi proses pembelajaran yang diberikan oleh dewan guru dengan media atau APE yang menyenangkan bagi anak seperti APE bahan alam. Dengan adanya APE yang menyenangkan diharapakan membuat suasana pembelajaran didalam kelas lebih menarik dan dapat meningkatkan kreativitas peserta didik.

\section{KESIMPULAN DAN SARAN \\ Kesimpulan}

Berdasarkan hasil analisis dan pembahasan yang telah dijelaskan pada bab sebelumnya, maka kesimpulan dari penelitian ini adalah:

1. Ada pengaruh media pembelajaran audio visual terhadap hasil pengembangan bahasa anak kelas B di RA Al Khodijah Purworejo Ngunut Tulungagung. Hal tersebut 
ditunjukkan dari uji paired t test pengembangan bahasa anak antara sebelum dan sesudah pembelajaran media audio visual didapatkan $p$ value $0,000<0,05$.

2. Ada pengaruh alat peraga edukatif terhadap hasil pengembangan bahasa anak kelas B di RA Al Khodijah Purworejo Ngunut Tulungagung. Hal tersebut ditunjukkan dari uji paired t test pengembangan bahasa anak antara sebelum dan sesudah pembelajaran dengan alat peraga edukatif didapatkan $p$ value $0,000<0,05$.

3. Ada perbedaan pengaruh media pembelajaran audio visual dan alat peraga edukatif terhadap hasil pengembangan bahasa anak kelas B di RA Al Khodijah Purworejo Ngunut Tulungagung. Hal tersebut ditunjukkan dari uji independen $t$ test pengaruh media pembelajaran audio visual dan alat peraga edukatif terhadap hasil pengembangan bahasa anak didapatkan $\mathrm{p}$ value $0,004<0,05$.

\section{Saran}

Berdasarkan kesimpulan dari hasil penelitian diatas, maka penulis memberikan saran sebagai berikut:

1. Kepada guru hendaknya memanfaatkan media yang tersedia di sekitar lingkungan sekolah untuk menyalurkan ide-ide kreatif anak agar dalam pembelajaran tidak membuat anak jenuh dan memberi variasi-variasi dalam pembelajaran guna meningkatkan pengembangan bahasa anak.

2. Kepada orang tua anak didik hendaknya selalu memberikan bimbingan, motivasi, stimulasi kepada anak bagaimana mengembangkan kemampuan bahasa anak dengan memanfaatkan media yang ada di lingkungan sekitar. 


\section{DAFTAR PUSTAKA}

Asyhar, Rayanda. (2011). Kreatif Mengembangkan Media Pembelajaran. Jakarta: Gaung Persada (GP) Press.

Fadhillah, N., Lubis, M. H., Sinar, T. S., \& Setia, E. (2019). Translation strategies used in Indonesian translation of Acehnese poem "Munajat Perempuan Sufi Aceh Pocut di Beutong.". International Journal of Innovation, Creativity and Change, 9(4), 172-182.

Hanifah, Trisna. (2014). Pemanfaatan Media Pop-Up Book Berbasis Tematik.Jurnal Early Childhood Education Papers. (Online). http://journal.unnes.ac.id/sju/index.php/belia. Volume 3 Nomor 2 Tahun 2014. Diakses pada 6 November 2019.

Khalsiah, M., Apridar, N. F., \& Ratri Candrasari, J. (2020). Fiction and Nonfiction Novel: Characteristics Possessed To Allure The Reader. Journal of Talent Development and Excellence, 12(1), 2081-2088.

Mansur. (2011). Pendidikan Anak Usia Dini dalam Islam. Yogyakarta: Pustaka Pelajar.

Masitoh. Strategi Pembelajaran TK. Jakarta: Universitas Terbuka.

Peraturan Menteri Pendidikan dan Kebudayaan Republik Indonesia Nomor 137 Tahun 2014 Tentang Standar Tingkat Pencapaian Perkembangan Anak.

Rolina Nelva. (2012). Alat Permainan Edukatif. Penerbit Ombak: Yogyakarta.

Suhartono. (2005). Pengembangan keterampilan bicara anak usia dini. Depdiknas, Jakarta.

Wijayanto, A., \& Susanto, S. (2018). Norma Komponen Pembibitan Olahraga Anak Madrasah Ibtidaiyah Usia 10 Sampai 12 Tahun Se-Kabupaten Tulungagung. JURNAL SEGAR, 7(1), 1-10.

Wijayanto, A. (2018). Pengaruh Latihan Renang Teratur Dan Latihan Renang Tidak Teratur Terhadap Kadar Trigliserida Plasma Pada Rattus norvegicus. Biotropic The Journal of Tropical biology, 2(1), 24-40.

Wijayanto, A., Hakim, A. A., \& Iffah, N. (2020). Pengaruh Metode Pembelajaran Movement Exploration Dan Metode Pembelajaran Guided Discovery Serta Persepsi Kinestetik Terhadap Hasil Belajar Lay Up Bolabasket Pada Mahasiswa IAIN Tulungagung. JURNAL SEGAR, 9(1), 1-13.

Wijayanto, A. (2018). Pengaruh Metode Guided Discovery, Dan Metode Movement Exploration Serta Persepsi Kinestetik Terhadap Hasil Belajar Pukulan Atas Bulutangkis Pada Mahasiswa IAIN Tulungagung. Halaman Olahraga Nusantara (Jurnal Ilmu Keolahragaan), 1(2), 160-176. 
Yuliani Nuraini Sujiono, (2009), Buku Ajar Konsep Dasar Pendidikan Anak Usia Dini, Jakarta: Indeks.

Yuniarti Sri. (2014). Asuhan Tumbuh Kembang. PT Refika Aditama: Bandung.

Wijayanto, A. (2018). PENGARUH METODE GUIDED DISCOVERY, DAN METODE MOVEMENT EXPLORATION SERTA PERSEPSI KINESTETIK TERHADAP HASIL BELAJAR PUKULAN ATAS BULUTANGKIS PADA MAHASISWA IAIN TULUNGAGUNG. Halaman Olahraga Nusantara (Jurnal Ilmu Keolahragaan), 1(2), $160-176$.

Wijayanto, A. Budijanto. 2011. Software Sistem Informasi Penggunaan Energi dan Kebutuhan Kalori. Jurnal IPTEK Olahraga KEMENEGPORA, 13, 1411-0016.

Lani, A., \& Wijayanto, A. (2020). PEMBUATAN SOFTWARE PEMANDUAN MINAT BAKAT (PEMIKAT) OLAHRAGA PADA ANAK SLTP BERBASIS ARTIFICIAL INTELEGENCE. JSKK (Jurnal Sains Keolahragaan dan Kesehatan), 4(2), 47-58.

Wijayanto, A., Hadi, M. I., SYAHRUDDIN, S., SUSIONO, R., KRISTINA, P. C., PRAHASTARA, P., ... \& ANDYARINI, E. N. (2020). BUNGA RAMPAI ANAK BANGSA INTEGRASI ILMU KEOLAHRAGAAN Dalam Preventif Pandemi COVID-19.

Wijayanto, A., Or, S., Kom, S., Kurniawan, A. D. A. W., Putro, B. N., \& Pengantar, K. Prof. Dr. ME Winarno, M. Pd., dkk.

Wijayanto, A., \& Susanto, S. (2018). Norma Komponen Pembibitan Olahraga Anak Madrasah Ibtidaiyah Usia 10 Sampai 12 Tahun Se-Kabupaten Tulungagung. JURNAL SEGAR, 7(1), 1-10.

Wijayanto, A., Or, S., \& Kom, S. PEMANFAATAN TEKNOLOGI VIRTUAL LEARNING PADA PERKULIAHAN OLAHRAGA OUTBOND SELAMA GEMPURAN COVID-19. Bunga Rampai, 1.

Wijayanto, A. (2018). PENDAMPINGAN PENGGUNAAN MOLASSES DALAM MEMPERCEPAT PENGOLAHAN DAN PEMANFAATAN FESES TERNAK UNTUK PEMBUATAN PUPUK ORGANIK. JPM Pambudi, 2(1), 1-12.

Asrifan, A. (2009). Using songs in teaching English language for the young learners. ParePare: unpublished.

Puasa, K., Asrifan, A., \& Chen, Y. (2017). Classroom Talk in Bilingual Class Interaction. Research in Pedagogy, 7(1), 106-121. 
Nadirah, N., Tahir, M. H., \& Asrifan, A. (2019). THE ABILITY TO TRANSLATE ENGLISH PHRASES INTO INDONESIAN AND THE DIFFICULTIES FACED BY THE ELEVENTH GRADE STUDENTS OF SMAN 1 PANCARIJANG. JOURNAL OF ADVANCED ENGLISH STUDIES, 2(1), 41-46.

Apdy, A. P. R., \& Asrifan, A. (2019, April). The Chinese mime game in teaching vocabulary on EFL classroom. In PROCEEDINGS OF THE 65th TEFLIN INTERNATIONAL CONFERENCE (Vol. 65, No. 01).

Taslim, T., Asrifan, A., Chen, Y., \& Nurdania, N. R. (2019). CORRELATION BETWEEN STUDENT'S VOCABULARY MASTERY AND SPEAKING SKILL. JOURNAL OF ADVANCED ENGLISH STUDIES, 2(2), 65-76.

Muthmainnah, M., Asrifan, A., Al Yakin, A., \& Sahabuddin, C. (2019, April). The use of dictogloss technique on ELT classroom: An experiment study of students listening comprehension. In PROCEEDINGS OF THE 65th TEFLIN INTERNATIONAL CONFERENCE (Vol. 65, No. 01).

Mutmainnah, M., Azis, S., Maulidya, U., \& Asrifan, A. (2017). Glory Style in Mandar Song Lyrics: A study of Mandar Tribe in South Sulawesi, Indonesia. JOURNAL OF ADVANCES IN LINGUISTICS, 8(1), 1286-1291.

Asrifan, A., Rinantanti, Y., Tang, S., \& Nadirah, N. (2019). THE 3-DIMENSION PICTURES IN INCREASING THE STUDENTS ABILITY AND INTEREST TO WRITE DESCRIPTIVE COMPOSITION. JOURNAL OF ADVANCED ENGLISH STUDIES, 2(1), 19-30.

Asrifan, A., Nadira, N., \& Haedar, H. (2018). IMPROVING STUDENTS'READING COMPREHENSION OF DESCRIPTIVE TEXT THROUGH COLLABORATIVE MURDER. JOURNAL OF ADVANCED ENGLISH STUDIES, 1(2), 21-31.

Asrifan, A. (2015). Analysis of English Students' Learning Style in Bilingual Class. International Journal of Literature and Arts, 3(4), 34.

Farahdiba, S., \& Asrifan, A. (2016). Speaking Ability and Psychological Barriers of the Second Year Students of Hotel Department of SMKN 1 Sidenreng Kabupaten Sidrap in Speaking English. Asian EFL Journal, (89), 41.

Asrifan, A. (2012). Increasing the Students Ability to Write Descriptive Composition at SMP Negeri 13 Parepare by using the 3-Dimension Pictures.

Tang, S., Asrifan, A., Chen, Y., Haedar, H., \& Agussalim, M. (2019). THE HUMOR STORY IN TEACHING READING COMPREHENSION. JOURNAL OF ADVANCED ENGLISH STUDIES, 2(2), 77-87. 
Nurwanti, N., Asrifan, A., \& Haedar, H. (2019). THE APPLICATION OF COOPERATIVE LEARNING: JIGSAW II TECHNIQUE IN IMPROVING STUDENTS'READING COMPREHENSION OF EXPOSITORY TEXT. JOURNAL OF ADVANCED ENGLISH STUDIES, 2(1), 31-40.

Asrifan, A. (2016). The Effectiveness of Think-Pair-Share Technique in Improving Studentsâ€TM Speaking Ability and Interest. English Literature and Language Review, 2(3), 24-35.

Asrifan, A., Muthmainnah, M., Al-Yakin, A., Sahabuddin, C., \& Haedar, H. (2018). THE CAUSE-EFFECT TECHNIQUE IN TEACHING RECOUNT WRITING. JOURNAL OF ADVANCED ENGLISH STUDIES, 1(2), 63-72.

Asrifan, A., Vargheese, K. J., Syamsu, T., \& Amir, M. (2020). ESP COURSE DESIGN: THE NEED ANALYSIS ON TOURISM DEPARTMENT IN INDONESIA VOCATIONAL HIGH SCHOOLS. JOURNAL OF ADVANCED ENGLISH STUDIES, 3(2), 69-77.

Asrifan, A., Ghofur, A., \& Azizah, N. (2020). Cheating Behavior in EFL Classroom (A Case Study at Elementary School in Sidenreng Rappang Regency). OKARA: Jurnal Bahasa dan Sastra, 14(2), 279-297.

Nadirah, N., Asrifan, A., Vargheese, K. J., \& Haedar, H. (2020). INTERACTIVE MULTIMEDIA IN EFL CLASSROOM: A STUDY OF TEACHING READING COMPREHENSION AT JUNIOR HIGH SCHOOL IN INDONESIA. JOURNAL OF ADVANCED ENGLISH STUDIES, 3(2), 131-145.

Muthmainnah, A. R., Atmowardoyo, H., Salija, K., \& Asrifan, A. (2020). Literary Work as Teaching Materials: A Study of Students and Lecturers Needs Analysis. Solid State Technology, 63(5), 394-407.

Tilome, A. A., Agustang, A., Jasruddin, M. S., \& Asrifan, A. (2020). Social Exchange of Political Elites in the Regional Leader Election of Gorontalo Province, Indonesia. Solid State Technology, 63(5), 521-531.

Pacinongi, A., \& Asrifan, A. (2020). Bimbingan Pengawas Berkelanjutan dalam Mewujudkan Pendidikan Karakter Bangsa dalam Kegiatan Belajar Mengajar Penjaskes. Celebes Education Review, 2(1), 1-7.

Gunawan, G., \& Asrifan, A. (2020). Penerapan Kerja Kelompok Kegiatan MGMP Guru Ekonomi dalam Menyusun RPP untuk Meningkatkan Kompetensi Pedagogik. Celebes Education Review, 2(1), 31-36.

Yusuf, I., \& Asrifan, A. PENINGKATAN AKTIVITAS KOLABORASI PEMBELAJARAN FISIKA MELALUI PENDEKATAN STEM DENGAN 
PURWARUPA PADA SISWA KELAS XI IPA SMAN 5 YOGYAKARTA. Editorial Team, 32.

Al Yakin, A., Sahabuddin, C., Rahayu, A., Fitrah, N., \& Arifin, M. (2020). Political Celebrification and Electability: A Study of Political Phenomena Imaging in Election Polewali Mandar District, West Sulawesi, Indonesia. Solid State Technology, 63(5), 632-646.

Junaedah, S. B. T., \& Ahmad, M. A. (2020). The Outdoor Learning Modules Based on Traditional Games in Improving Prosocial Behaviour of Early Childhood. International Education Studies, 13(10).

Octaberlina, L. R., \& Muslimin, A. I. (2020). Efl students perspective towards online learning barriers and alternatives using moodle/google classroom during covid-19 pandemic. International Journal of Higher Education, 9(6), 1-9.

Octaberlina, L. R., \& Anggarini, I. F. (2020). Teaching vocabulary through picture cards in Islamic Elementary School: a case study in Nida Suksa School, Thailand. Jurnal Madrasah, 13(1), 26-38.

Octaberlina, L. R. (2016). Plagiarism in English language theses in Indonesia. Jurnal Ilmu Pendidikan, 14(3).

Octaberlina, L. R., \& Anggarini, I. F. (2020). Teaching vocabulary through picture cards in Islamic Elementary School: a case study in Nida Suksa School, Thailand. Jurnal Madrasah, 13(1), 26-38.

Octaberlina, L. R., Anggarini, I. F., \& Muslimin, A. I. (2020). Virtual English teaching in remote area: a case study. Journal of Critical Reviews, 7(19), 9707-9713.

Amalia, L. L. (2019). REFLECTIVE PRACTICE AND SELF-IDENTITY AS PARTS OF PROFESSIONAL DEVELOPMENT: A SURVEY IN A TERTIARY LEVEL. E-Link Journal, 6(1), 160-163.

Asrifan, A., Zita, C. T., Vargheese, K. J., Syamsu, T., \& Amir, M. (2020). THE EFFECTS OF CALL (COMPUTER ASSISTED LANGUAGE LEARNING) TOWARD THE STUDENTS'ENGLISH ACHIEVEMENT AND ATTITUDE. JOURNAL OF ADVANCED ENGLISH STUDIES, 3(2), 94-106.

Asrifan, A. (2021). ACADEMIC WRITING. LawArXiv. January, 2. https://doi.org/10.31228/osf.io/x2s7e

Asrifan, A. (2020). TUTORIAL PENGGUNAAN QUIZIZZ (www. quizizz. com) PADA PEMBELAJARAN. https://doi.org/10.31219/osf.io/kqnza 
Asrifan, A. (2021). Abd Ghofur.“. THE USE OF READING CIRCLES IN INCREASING STUDENTS SPEAKING ABILITY AT THE ELEVENTH GRADE SMK NEGERI, 1. https://doi.org/10.31219/osf.io/8vjxy

Asrifan, A. (2020). Pandemic, Humanity and Education. https://doi.org/10.31219/osf.io/q2gpk

Asrifan, A. (2021). USING CAT AND MOUSE GAME TO IMPROVE STUDENT'S SPEAKING ABILITY AT THE ELEVENTH GRADE OF MA YMPI RAPPANG. https://doi.org/10.31219/osf.io/phtvn

Asrifan, A., \& Ghofur, A. (2021). THE USE OF READING CIRCLES IN INCREASING STUDENTS SPEAKING ABILITY AT THE ELEVENTH GRADE SMK NEGERI 1 PANCARIJANG. https://doi.org/10.31219/osf.io/8vjxy

Asrifan, A. (2021). Book Review: Halliday. 1989. Spoken and Written Language. Oxford University Press. https://doi.org/10.31219/osf.io/ej8tb

Asrifan, A., \& Ghofur, A. (2021). TALK, ACTION, SILENCE, INTERRUPTION AND THEIR IMPLICATIONS IN BUGINESE SOCIETY (SOPPENG REGENCY). https://doi.org/10.31219/osf.io/pv3ku

Asrifan, A. (2020). PENILAIAN BERBASIS ANDROID MENGGUNAKAN APLIKASI PLICKERS. https://doi.org/10.31219/osf.io/htreq

Asrifan, Andi, Octaberlina, L. R., \& Agus, Selviana. (2021, January 8). IMPROVING STUDENTS' SPEAKING ABILITY THROUGH SIMULATION OF JOB INTERVIEW. Zenodo. http://doi.org/10.5281/zenodo.4428778

Andi Asrifan, Like Raskova Octaberlina, \& Eka Safitri. (2021, January 8). THE EFFECTIVENESS OF USING RECITATIVE METHOD TO IMPROVE STUDENTS' VOCABULARY MASTERY. Zenodo. http://doi.org/10.5281/zenodo.4428303 
